\title{
El Arte del Grabado en España
}

\author{
Por RAMON FARALDO
}

Seguramente mi primer deber ante ustedes, que han cometido la temeridad de venir a escucharme es el de justificar mi presencia, ya que la presencia de la exposición se justifica por sí sola.

Mi presencia aquí se debe a dos razones. La primera es cosa mía, $y$, por ello, puede quedarse en buena voluntad: la de contribuír a explicarles, por qué esta rama de arte de España es como es y no de otra manera.

La segunda no se refiere a mí, no es una tentativa, sino un hecho que equivale a una victoria: el hecho de que el grabado español haya venido en su manifestación más completa a tierra hispanoamericana, y no a otra tierra. Parto, naturalmentelde la convicción de que mi modesto testimonio no resulta imprescindible para que éste arte sea dignificado, ni para que sea comprendido. Simplemente se ha procurado que la palabra acompañe el signo, a fin de que la entrega sea más completa.

La primera de aquella dos razones me llevará a hablarles del instinto de grabar, viejo como las manos de los hombres, viejo como su inclinación a acariciar y a herir, a destruir y a jugar.

¡Oh, sucesión del arte, - dice Malraux - que tiene tal necesidad de los hombres para ser explicada! Exactamente. Ninguna teoría de que aquí pueda ser objeto va a llevarnos más allá o más acá del hombre. Probablemente, éste se dió cuenta, un día anterior a la civilización un día en que el hombre era aun una especie de gorila, mucho antes de que la civilización otorgase a los gorilas la facultad de confundirse con bastantes especies de hombres, descubrió que el relieve de una piedra dura, apretado sobre otra más blanda, dejaba en esta una huella, una señal; un signo. Y se puso a pensar para qué podría servirle aquello.

Igual le sucedió cuando vió brotar una chispa del corazón de una piedra: cuando vió por primera vez el brillo del fuego. El fuego y el 
signo se parecen en estas otras cosas. Ambos necen de las piedras por intermedio del hombre. Ambos van a servir combustible a su cuerpo o a su sueño. Ambos le servirán para sembrar de luz caos su camino bajo las estrellas.

Papillon contó que, antes del diluvio, los hombres grababan sobre los árboles la historia de los tiempos, de las ciencias y de las religiones y como durante la ceremonia de un sacrificio ofrecido a los dioses, en la víspera de una batalla; el héroe Agesilas, para dar confianza a sus soldados, tuvo la astucia de imprimir en el hígado de la víctima augural, la palabra victoria, previamente grabada en un cuño escondido en la palma de su mano.

Lentamente, los seres humanos se persuaden de que, por una mecánica grabatoria, podían dar significado permanente a aquello que les interesaba. Es un procedimiento de grabado el que utiliza la humanidad para legitimar un descubrimiento utilísimo, y decorador: la moneda. El dinero, que es inventado y acuñado por los hombres, y en el que éstos esculpen sus cabezas, para acabar, el dinero inventado acuñado, y quedándose definitivamente con la cabeza de los hombres.

Plinio escribe la primera alabanza del arte de los grabadores: "Invención que debía ser envidiada por los propios dioses, porque arrancó de la muerte, y del olvido los rasgos de los inmortales: porque ayudó a crear inmortalidad".

Plinio escribe con soberbia. Nadachăy sobre la tierra que sea inventado. Debió hablar con más justeza de descubrimiento. Es casi humillante, por cierto, pensar que lo que invita al genio humano a establecer su majestad sobre el planeta suele ser fruto de la casualidad. Lo que los hombres inventan ya estaba inventado mucho antes: ellos se limitan a descubrirlo y, desde luego, a explotarlo. Pablo Picasso nos ha confiado que él no pinta lo que busca, sino lo que encuentra. Picasso tiene razón, en cuanto a él y en cuanto a su especie en general. El hombre jamás ha buscado nada. Se ha limitado a ir encontrando lo que ha podido y como ha podido. Partiendo de esta modesta convicción es posible que los hombres hubieran inventado algo menos y llegado a saber algo más. Hasta es posible que hubieran llegado a saber algo más de sí mismos. Pero los hombres no saben más que encontrar. Algún día debieron encontrar que, impregnando con un colorante una impresión en relieve, este relieve podía fijarse sobre la superficie preparada al efecto, un tejido, una lámina de hueso o de marfil. Así vino a conocer una fuerza nueva; la de poder vivir en símbolos grabados más allá de su muerte y de su espacio. Lo que éste hecho aclaró para 
siempre fué la majestad del signo, escrito o grabado, sobre la fugacidad del hombre.

Una nueva artesanía se dedica a aplicar y perfeccionar el descubrimiento. La madera suplanta a la piedra. La imagen ilustra al signo. El entintado simplifica la tarea del cuño. Los dos adolescentes, Alborico Cunio y su hermana Isabel, en la Ravena del Trecento, tallan en planchas de madera de ciprés de su jardín, con una navajita, "los caballerescos hechos del gran Alejandro", los imprimen con jugo de moras y los envían a Honorio IV y a su magnífica corte que se maravilla ante el prodigio. Entonces empieza la gran gestación.

Aparecen los cándidos tatuajes de la xilografía medieval ilustrando los libros de horas y los libros de caballería de la alta Edad Media. Batallas, torneos, cortejos celestes o reales, toman cuerpo gráfico en las tablillas socavadas. Las razas del sol, el milenario Oriente se enorgullecerá de poseer la fórmula mágica mucho antes. Pero lo cierto es que ésta no adquiere impulso hasta que los pueblos de la niebla, las razas gremiales y artesanas por excelencia, neerlandeses y tudescos le aplican su tenacidad y su laboriosidad.

En la vieja e infatigable Europa es el prodigio: aquel signo solitario que, un hombre hizo en una piedra se convierte en muchedumbre de signos, la piedra en metal maleable, la hoja de marfil en hoja de papel. Los plateros Gutemberg y Urich Zell hacen oír a Occidente un sonido nuevo, que es casi el llanto bautismal de su cultura : el sonido de la imprenta.

Pero existe, en "este proceso, un ladond exactamente utilitario, que no pertenece a plateros, orfebres, ni caleógrafos de naipes y medallas. Pertenece a un linaje de hombres que cuando vieron el tatuaje en una piedra no pensaron "qué hermoso podría ser si sirviera para algo", sino que pensaron "qué hermoso podría ser, si no sirviera para nada más que para hacer soñar".

Era el linaje de los inútiles, de los aventureros del alma, de los soñadores: de los artistas. Ellos también van dejando su testimonio escrito a través de las eras.

Punta de metal contra superficie de metal, rayando la plancha de cobre a fuerza de fuerza : la aplicación del ácido nítrico viene a simplificar y sensibilizar el procedimiento. Siglo tras siglo, las sombras de estos obsesos se suceden, acumulando horas de ensimismamiento en los estudios rodeados de bruma báltica o de sol florentino.

Sombras de los esmaltistas, caleógrafos y niellatorisflorentino de Maso Finisquerra, amigo del Pollaido, que invierte la técnica de grabar : de Baldini Sandro Botticelli, con quien se incorporan a la estria del buril 


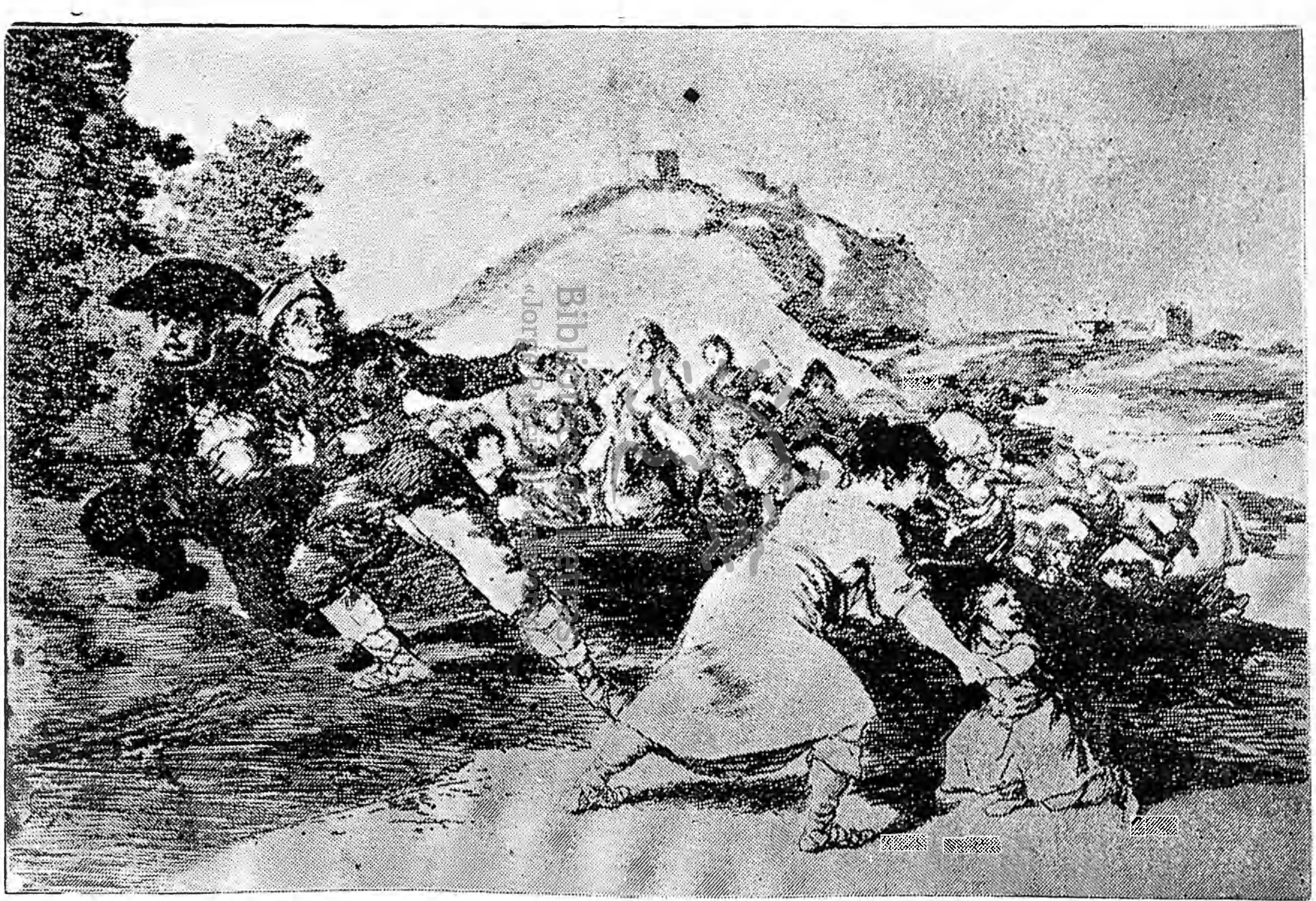

LOS DESASTRES DE LA GUERRA: "YO LO VI". (aguafuerte, agua tinta y punta seca). 


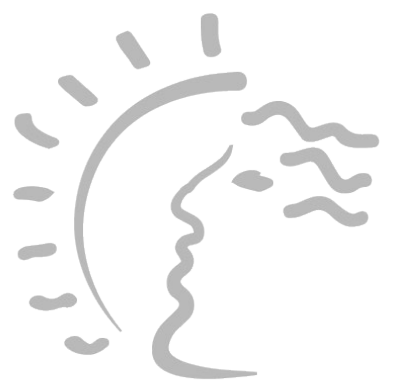

Biblioteca de Letras

«Jorge Puccinelli Converso» 
los óvalos indolentes del. Renacimiento. Andrea Mantegua grabador de triunfos cesáreos y óperas atlánticas; sus émulos de Múnica, Nuremberg, Westlalia, Martin, Schonganer, Potter, Ruisdael, Claude, Lorrain, SaintAubin ....., grabar ya no es una curiosidad, sino una pasión, y su fiebre se propaga a hombros de los ríos de la cultura, el Rhin, el Tíber, el Escalda, el Sena.

En esta promoción secular dos grandes nombres se açigantan. Los dos son nórdicos, los dos nacen y crean en tierras de frío, como si el impulso de grabar obedeciese a las mismas razones que la necesidad de encender el fuego.

Una es la de Alberto Durero, visionario de Patmos, orfebre brevilista, hijo de obrero, obrero él mismo. ¿No resulta singular, que la elevación de la artesanía del grabado a arte del grabado sea efectuada por manos artesanas? Pero asi ocurre: Durero es el primer analista, el histólogo de la plancha de cobre. El trata sus hormas como un broquelador de monedas, incluso consciente de que en esa metalurgia su alma es la primera materia laminada, la "Muerte", la "Melancolía", son las pruebas seculares de tal vocación y de tal impiedad los indicios de una ciencia gráfica que es también una sabiduría masoquista.

Si Durero es el histólogo, Rembrandt Hammerzon va a ser el orquestador, el Juan Sebastián Bach, el buriel el organista mayor de la espe. cie, el Greco en el ámbito del color, Rembrandt escucha la posibilidad melódica de tintes y rayas, antes incluso de verlas. Saberlo creador es tan musical como gráfico. Su visión es audible. El nos hace oír, tanto como ver, el roce eléctriç de unciabelio contra otro cabello, el posible rumor de las hebras de un tejido, el cántico de las grandes penumbras sagradas. He aquí un sistema lineal que es también un sistema orquestal. Resonancias en un gran adagio, agudas mofético profundas, que se acordan si la música tuviera un cuerpo dibujable y ese cuerpo reconociese el tránsito transcurso del alba y del ocaso, Rembrandt, seguramente nos daría las luces y las sombras.

En este mapa del arte del buril; ¿dónde está España? ¿Qué lugar le corresponde?

Los artistas españoles no descubren el grabado. En general los artistas españoles no descubren las grandes técnicas ni los grandes formatos estilísticos. Ningún procedimiento real o accesorio de la elaboración artística se ha descubierto allí, ni el gérmen gótico, ni el barroco, ni el procedimiento del óleo, ni de las estatuas, ni el del grabado, son revelaciones españolas.

Pero si es justo admitir esto, no es menos justo admitir que, a defecto de originalidad en la estructura la misión de elaboración de aquella 
raza parece ser substanciarlos o vitalizarlos inaudite. Esta raza no elcrbora: arde. Su actividad no es la cocción, sino la ignición. Desdeña el tiempo e ignora la tradición en la medida en que es apta para repentizar tiempo y tradición, sus artistas carecen de la virtud hacedora de hormas y hormatos; pero lo justo es reconocer que ellos han puesto a menudo el fuego allí donde los demás han puesto habitualmente la leña.

Y lo que les digo: ¿en qué va a convertirse el delicado aparejo de los cinceladores nipones, de los burilistas de la dulce Francia y de la florida Holanda, cuando su artificio entra en conexión con la expeditiva biología de los artistas de España?

La técnica llega allí madura : trillada, tamizada, y glorificada. Mas, por una razón o por otra tal vez para proporcionar un nuevo argumento al nudeo de repudiciones que caracteriza la creación plástica ibera, nuestros maestros de los siglos clásicos no la ejercitan apenas. Hay alguna pieza grabada de Velásquez, alguna de Valdés Leal y de Alonso Cano. El viejo Ribera, en su taller del Turia, escruta con mayor asiduidad el enigma del aguafuerte. Poseemos un número breve do poderosas figuraciones de su firma: pero, hasta este momento, el grabado no pasa de experimentación ocasional. No ocupa ni preocupa suficientemente para constituir un linaje de arte.

$\mathrm{Su}$ vida es lánguida. Los Borbones, que fomentan su cultivo no consiguen gran cosa. Promueven, eso sí, alguno que otro exquisito especialista en efigies tilustres. Crean una Academia en la que dicta su enseñanza Palomino y de la que brotan Carmona, Ametller etc...... Las reales prensas de Carlos III propalan' suis límpidás estampaciones.

Una Academia ..... Pero es que el Arte de España ha nacido alguna vez en la Academia, ha dejado de nacer alguna vez en la intemperie? Este arte no se produce por experiencias, sino descargas. Los nombres citados no alcanzan categoría de creadores, sino a lo sumo de intro. ductores. Sus hechos no crean historia del arte.

Es que esta historia, hablando siempre en los términos de nuestra gente, dejan de hacerla los hombres : la hace un hombre, por un golpe de mano.

No se gana en mancomunidad y por los años; se gana en soledad y por la persona. No se hace; se nace, se vive, se mueve. "La tradición soy yo", parecen decirnos los absolutistas plásticos de la raza.

La tradición de la pintura clásica hispana se llama Diego Velásquez, ese loco divino mezcla de Séneca y de Hamlet; ser o no ser fué para él pintar o no pintar. La tradición arquitectónica se llama Herrera ese lobo solitario del arte de construir Escoriales, Babeles funerarias, tan inexplicable hoy, como hace cuatro siglos o veinte siglos. 
La tradición grabadora española va a llamarse Francisco de Goya.

Permítanme insistir en lo dicho: dentro de nuestras fronteras, el espécimen genial no nace con más frecuencia que en otros sitios; pero, cuando nace, pueden albergarse grandes probabilidades de que cierta relación milenaria con el cosmo será rota, y de que un nuəvo cosmo y una nueva relación van a producirse.

Nada hacía vaticinable al Goya, grabador y aguafortista. Ni la estricta discreción con que éste arte era cultivado en su tiempo. Ni la línea que podía nacer de los maestros europeos. Ni la que podía nacer de los nuestros : ni desde luego, la que podía nacer del propio Goya. Muerto, antes de empuñar el buril calcográfico, Goya hubiera desaparecido sin suponerse a sí mismo, y sin permitir su suposición a los demás. Con él se hubiera extinguido, a lo sumo, un pintor de buen gusto un decorador a lo tiépolo, adoptador español de los primeros gobelinos; un émulo de Watteau con vaga caligrafía ibérica.

Pero un día, su destino le dobla sobre la piedra litográfica, sobre la plancha de cobre. Pone entre sus dedos una lanceta de grabar. El hecho va a producirse; Goya empieza a trazar sus notas de sociedad, su teatrillo de cámara, sus retratos privados, bastantes distintos, dicho sea de paso, de aquellos que le hacían pintar sus majestades barbónicas y los cisnes, empelucados de su séquito.

Hoy, a la vista de los gráficos que documentan su terrible travesía, estamos facultados ahora para opinar que, si Goya empleó la piedra litográfica, fué porque la piedraconstituye el utill bíblico de la lapidación. Si otras veces utiliza metal y ácido nítrico para sus grabaciones, es porque el metal sirve lo mismo para trazar una línea que para tejer jaula. Y porque el ácido nítrico, en la droguería moderna, es el sucedáneo químico de la "lata morgara", el cagua de la destrucción de la alquimia legendaria.

Estas materias van a reivindicar en sus manos, además de una eficacia gráfica desconocida, su cruento y primario poder, su naturaleza purgatorial. Ello no prejuzga la calidad del arte, goyesco, pero puede ilustrarnos respecto a la condición beligerante del mismo.

Goya no salta a la jerarquía trazada por los grandes artistas, augures de su raza. Por el grafista del bisonte bermellón de Altamira, incomprensible Picasso del subsuelo, neolítico. Por Velásquez, Len implacablemente anárquico en su serenidad. No falta a la fatalidad de la tradición pasada ni a la fatalidad de la tradición futura. No falta a Pablo Picasso, ni a Juan Gris, ni a Juan Miró. De su pulso destila petróleo, el mismo clamor. Como en ellos, el lema de su arte va a ser agotar lo inagotable; razonar absurdo penetrar en la muerte. 
Con el último arropado y delicioso procedimiento caligráfico, que había servido a los grabadores de otros países para hacer naipes, rostros olímpicos, paisajes adorables. Goya va a hacer patíbulos. Paredes de ejecución, desmontes el escarnio y la locura. Va a hacer amueblados por un pudridero, va a clavar en sus estacas las diversas inscripciones a que le obliga la buena educación.

Había sido un arte gremial, adjetivamente lírico. El va a hacerlo personal hasta las uñas y vital hasta la sangre. Al tomarlo en sus manos, se produce en el acto un atentado contra la entidad misma del dispositivo que utiliza. De orfebrería y producto gráfico, pasa a ser producto orgánico. Pasa a ser cirugía, cuando no autopsia.

Dos grabadores, Durero y Rembrandt fueron dos visionarios, es decir, dos expectadores; a lo sumo dos soñadores. El uno sueña su Apocalipsis, el otro ante su Gólgota. Goya no sueña; comprueba porque no es un visionario, sino un testigo. Eventualmente, podrá ser también un acusado. Pero el papel que le va mejor, aquel en que se siente más a gusto, es el de gran maestro de ceremonias.

Y donde han quedado el rayo diurno de Durero, o el completo crepuscular melódico de Rembrandt ..... La iluminación goyesca va a ser habida de día y de noche, va a ser lo que queda de la madrugada después de su desecación por el paso de la muerte. La aguja que efectuara la sutura de esa atmósfera de sus transeuntes será una aguja de hiel y de sarcasmo, zurciendo verdades tan irreparables que él mismo no se atrevería a llamarles de otra forma que disparates o Caprichos.

Goya está soló. Esslibre! Comprende que Sư adversario no es la guerra, sino la creación. El diabolista Brueghel se había quedado en lo pintoresco, de las tentaciones. El dispone de un pueblo oscuro y visceral, que no es imaginado como el del flamenco sino captado, vomitado. La horda interior se encuentra, se reconoce en la otra que prueba los barrios del Madrid en guerra y del Madrid en Carnaval, dos formas distintas de la guerra entre los cuerpos y de la guerra entre las almas.

Así va trazando sus conjuros. Acude la lechuza, la soldadesca, la harpía, el ahorcado, el usurpador, la prostituta y el mono. Si han quedado lejos los encajes adorables de Claude Lorraine, las oquedades litúrgicas de Rembrandt. Estamos en la república negra de las sartenes, de los rabos, de las médulas cojas de quienes llevan la escoba por bandera y la careta de burro por cédula personal. Estamos en los espacios donde da su flor infernal. Aquí no hay más que los que van a morir y los que entierran aquello que han matado. Los rostros que ve no son los que él quiere ver. El quiere ver lo que hay detrás ...... Darles la vuelta, verles el forro, descubrir lo que esconden. Supone que cada rostro no 
es un relieve de carne, es un agujero, y se asoma al pozo y comprueba lo que suponía; comprueba hasta dónde una nariz puede ser un hocico, quijada una dentadura y charca un ojo, cuando se horroriza, cuando su pulso tiembla ante el cinismo de sus hallazgos, les pone una máscara. Se dice "el sueño de la razón produce monstruos". Y les oye decir : "pero los monstruos del sueño acaban produciendo razón".

A veces hasta bromea con esta fauna la dice cosas de una implacable urbanidad" ¡Tal para cuall "Mucho hay que chupar", "Para eso habéis nacido", o en fin la última suprema sentencia, "Todos morirán".

La guerra fuera, la guerra dentro. Descargas en las calles de Madrid, descargas debajo de sus párpados. El piensa que la guerra fué para que él, Goya, fuese como fueron para lo mismo, la avaricia, la lubricidad, la soberbia, la calumnia, bastardía de los hijos del hombre. De todo ello se apodera como si fuese suyo, exhibiéndolo sin humildad y $\sin$ arrogancia, como si exhibiese sus propias manos.

Todos los términos de la tradición técnica y temática del grabado han sido rotos. En realidad Goya no graba; saja, estirpa, la separación de sus tintas no se efectúa por la modulación, como Rembrandt, ni por la articulación lineal, como en Durero. Sus tintas no son graduadas, sino seccionadas. Su toque de grabador no se parece al de nadie, no es un procedimiento gráfico, sino un procedimiento judicial y prensa.

Claro está, todo ello no significaría gran cosa si no se expresase a través de una prodigiosa estructura gráfica. Aun aceptando que Rembrandt sea el arcángel, hà que convenir en que Goya es el dios del arte de grabar. El lo sabe todo lo puede todo en lo que se refiere a rayas y a tintas. Sus grabados son el verdadero Apocalipsis del rococó. La filigrana casi femenina del estilo dieciochesco, pero hecha vigor, hecha corazón de hombre. Qué exquisita música de cámara tocada por un león ...... Yo compraría su alucinante maravilla con la que puede observarse el microscopio en la pigmentación exquisita de una gota de sangre o de una sección de tejido nervioso. Así es de exacta, de vívida. La fuerza aterradora de Goya consiste en hacernos pensar que esa gota de sangre, en la que él vió todo lo que vió podía ser una gota de nuestra sangre.

¿Es ésta la obra de un ilustrador? ¿La literatura la ilustrará mucho más que ella ilustrará a la literatura? ¿Caricciura, documento onírico? Sus sueños se parecen a sus dibujos mucho menos que sus dibujos a sus sueños. Lo caricaturesco no es más que un juego. Lo goyesco no es menos que un mundo.

Tampoco es la obra de un moralista. Le divierte demasiado lo que revela para intentar reformarlo o hacerlo mejor. No hay en él piedad, ni 
ese mundo pudo soñar un publicista mejor que Goya ni Goya pudo soñar publicidad mejor para su genio que la de ese mundo. Y si, se niega a ser censor : conviene en ser su semejante, el Director de escena de la pantomima. Por lo demás, la intención moralista exige la reconocibilidad. Allí nada es reconocible. El se abstiene de señalar a nadie. Allí no hay más rastro que el suyo. Cualquiera de sus grabados mucho antes que ser esto o lo otro, es él. No es ni siquiera un Goya: es Goya. Para el destino del arte, se trata de otra cosa. Se trata de un hecho artístico autorizando un hecho vital. Señala el principio de una era en el que el arte va a decidirse "a no gustar". Nadie se había atrevido a tanto: la existencia arrojando la ficción. A la deformación estética de la vida va a sustituir una expresión más profunda; la pasión de la vida. Lo plástico ha dejado de ser una creación para convertirse en una criatura. Se trata, en suma, del comienzo genial del arte moderno, del tronco materno, de Van Gogh, Gutiérrez Solana y Pascin. De la primera coartada de Pablo Picasso. El otorga a España el derecho a reclamar para si los orígenes y la responsabilidad de todo lo que va a hacerse en arte hasta nuestros días.

Si las investigaciones gráficas de los artesanos nórdicos y mediterráneos conducirían a la invención de la imprenta y del libro, detrás de las suyas no podían venir más que el cine y la crónica de sucesos. El augura sí, la era moderna en toda su velocidad y en toda su intimidación. Por anunciarla, también es verdad, que no deja de anunciar el campo de concentración yala guerra fotal.etras

Goya también demuestra calgo más; demuestra por ejemplo, que la grandeza del genio puede prevalecer sobre la virulencia del hombre. Nos demuestra que lo que se llama eternidad no es la inercia de un sueño soberbio, sino un trabajo que continúa después de la muerte. Que el artista empieza a vivir en el tiempo que sigue a su muerte : que este tiempo y sus hechos no son el cumplimiento de una ley astral, sino el cumplimiento de su profecía. Y que, como les dije, la tradición, al menos en España, es la acción de un hombre solo, capaz de resumir en su gesto las consecuencias de un número determinado de siglos y de hombres, que le preceden y de un número indeterminado de siglos $\mathrm{y}$ de hombres que le continuarán.

Cuando Goya desaparece queda abierto el problema de los sucesores. No se puede beber de tal forma en las cepas de la raza que éstas no se esterilicen por algún tiempo. De Goya no puede decirse que sembró de sal la tierra que pisó, porque en la tlerra que pisó no dejó sitio ni para sembrar sal. 
Los que le siguen inmediatamente actúan bajo el pasmo de sus revelaciones: él había abierto el camino, y, a la vez, lo había cerrado con la enormidad de su presencia. José María Galván, primer grabador interesante después de Goya sirve a Goya y se alimenta de Goya. La carcajada de los locos, el cascabel de los carnavales goyescos se mezclan, irresistiblemente con la vocación de su buril. Galván reconoce a Goya, acaso porque entiende que una empresa tan grande no puede ser justificada por un solo hombre, por un solo Goya.

Algunos otros nos dejan, junto a Galván, recuerdos de una limpia orfebrería calcográfica : Bartolomé Maura, Rafael Esteve. Como Galván, preservan su dignidad prescindiendo de ser "originales", cosa en verdad muy difícil junto al gran aragonés. Prefieren reproducir las obras eternas de pintores españoles que iniciar una aventura personal en la que habían de ser eclipsados.

Son los hombres del romanticismo los que empiezan a reinvidicar al género. Promoción sombría, atravesada oscuramente por la esperanza de Dios, cuyo destino parecía configurado por una gran tiniebla y una luz, nada como el luto y los macilentos albas de la calcografía para relatar su sino, el sino de los grandes amantes de los grandes suicidas : y desesperados ingenuos quiero decir, el signo de los adorables.

El amor y la muerte son dos déspotas. Ellos los reconocen en el fatalismo acariciador de los entintados y las azucenas litográficas. Parcerisa y Bernardo Rico orlan así los poemas de los hombres que, a pesar de todo, aun creían en ld poesía: de los hombres que amaron tanto y naturalmente tuvieron tan mal fin.

Un artista de Cataluña viene a indicanos que la cepa no se había secado. Es Mariano Fortuny. Su misión es dejar patente que, en lo futuro, no sólo va a ser posible reproducir, sino producir : crear. Sorprende lo ágil y airoso de su técnica. Fortuny es un grabador excepcional en la medida que es un dibujante excepcional. Esto deben reconocerlo incluso los hombres del siglo que seguirán inmediatamente a su siglo, los hombres aquejados de una enfermedad terriblemente humana y terriblemente injusta: la de su prevención hacia aquello que constituye inmediatamente su pasado. No hay nada que repugne más y que comprenda menos el siglo XX que el siglo XIX. No sé por qué : tal vez a causa de parecerse demasiado a nosotros, o porque somos nosotros mismos, vestidos a la usanza de una moda que nos da pena, si no nos da risa. Puesto que no es ni leyenda ni presente puesto que no cabe ni en la nostalgia ni en la actualidad, no sabemos alojarlo más que en la zona del remordimiento, es decir, en lo que deseamos olvidar cuanto antes. 
Mariano Fortuny no se libra enteramente de esa vindicta. Ello no le impide ser un enérgico artífice. Fortuny muere a los 36 años, pero una vida tan breve le bastó para ensanchar los horizontes de la técnica, en la que hace penetrar el olor de Africa y la sal de Nápoles, con eléctricas y esbeltas incisiones. Por lo demás aunque intenta refinar su buril en la retórica de los incisores itálicos, los huesos que encubre ese elegante atavío siguen siendo los huesos de Goya.

Fortuny es, no obstante, un creador. El primer antídoto goyesco. Cuando nace el siglo XX, el arte de grabar es una actividad normal, en la que cada artista puede intentar su aventura. Se abre el fuero de los talentos individuales: Desde 1,900, los artistas pintores utilizan la piedra, el cobre, la punta-seca para experimentar como tales pintores, pero a dos luces. A su lado trabajan los puros, los fieles a la causa los que entienden la especialidad no como disciplina auxiliar, sino como substancia apasionante, cuyo secreto no se llama grabar, cuyo secreto se llama arte legítimo y autónomo.

Daniel Vásquez Díaz, ese suave, Durero andaluz, confía al aguafuerte la sangre fuerte de los toreros raciales.

El ejemplar más poderoso del arte moderno español, José Gutiérrez Solana, creador del nuevo gótico de suburbio, y, a la vez, de una manera hombruna y estremecedora de hacer arte medio, encuentra en el procedimiento litográfico un medio idóneo. Raras veces su dibujo-carcelario adquiere la eficacia que le presta la inscripción en piedra, o cuando su anaiema - si Goya es un cómplice, Solana es un evangelista- se realza por la mordedura del ácido nítrico.

Hay un artista, más bien solitario, no sé si un tanto desdeñado o un tanto desdeñoso, que vive su leyenda en una casa de piedra y de yedra del Pirineo. Este hombre, pintor, y narrador, halló en los laberintos de la tinta, una guarida más para esconder su melancolía.

Ricardo Baroja escucha a menudo y toma parte en el misterio de esta relojería gráfica, en su alambrado lineal, en su dulce tic-tac. Yo le he visto muchas veces, en tardes de lluvia, encorvado sobre sus planchas. Casi ciego, podría creerse que graba de oído, y auditiva, como en Rembrandt, parece ser, su inspiración : tejido de sus rayas es muy parecido al de la lluvia densa de su Navarra: cuyo rumor escucha, la poca luz que aún queda en sus ojos es la misma que queda después del anochecer, en alguna pared blanca de la aldea, en las ventanas en las que arden los fuegos campesinos.

Los grabadores forman ya un grupo extenso en España. Su arte posee una ciencia propia y un estilo diverso y rico. Si hay un movi- 


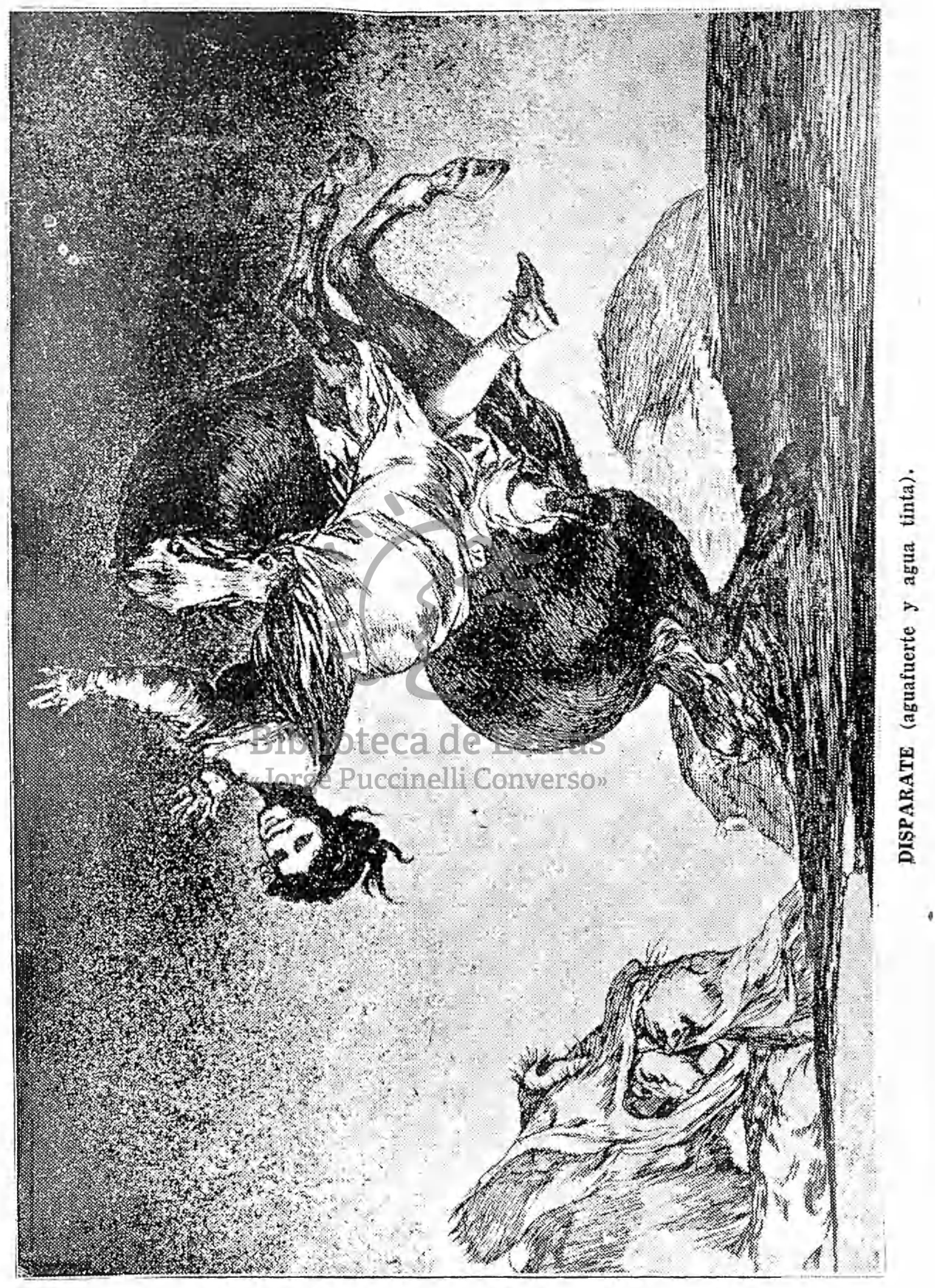




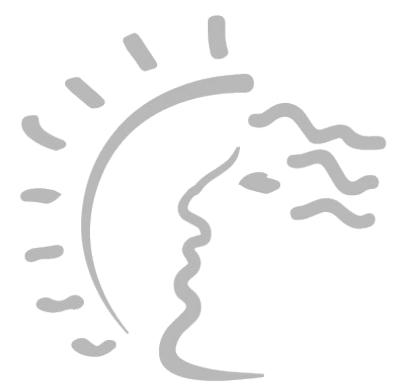

Biblioteca de Letras "Jorge Puccinelli Converso» 
miento que pueda designarlos es el del crecimiento. Predomina entre ellos una globulación muy alta de sangre septentrional, cantábrica y mediterránea, catalana y gallega. Ell propio Goya era un pirenaico, como lo es Ricardo Baroja: Nórdicos son Julio Prieto Nespereira, Castro Gil, Blanco del Riego, Lahoz, Hurtuna, Pla, Olle Pinell. Ella es singularmente la que confiere vitalidad a la clase grabadora, a través de la gestión del orensano Julio Prieto Nespereira, Presidente actual de la Agrupación Española de Artistas Grabadores. Agrupación que, desde hace 25 años, impulsa las exhibiciones, el conocimiento y la estimación del arte de grabar.

Tal vez deba verse, a propósito del predominio en materia litográfica de los hombres de Finisterre sobre los otros peninsulares, la fatalidad de una vocación que como en el caso de Baroja, se identifica con la psicología de un paisaje: Precisamente, del paisaje que convocan hasta el mar y la frontera lusitana, los carrillones de Compostela.

Las páginas de Prieto Nespereira son fieles a aquella umbría nativa, umbría de redes, pinares y piedras antiguas donde el fin del sol no constituye un hecho diurno, sino un hecho nocturno que se llama Via Láctea o Camino de Santiago. Es menos que luz, es sólo resplandor, un halo entre sombras. Su membrana de neblinas y estrellas nos aproxima bastante a las tramas amadas por los grabadores nacidos bajo el Manto del Apóstol.

Este es, más o menos el cómputo actual del grabado español. Le faltaba tradición y sebla hácreado en menos deeun siglo. Le faltaba confesionalidad y la fuerte Agrupación de Artistas Grabadores, vino a dársela. Le faltaba, en fin, el gran hecho que revalida su joven historia, y el gran hecho está aquí : un día su documentación atraviesa el Atlántico para instituir en tierra americana su testimonio. El estado español y la Agrupación citada cumplen esta gran etapa.

Esta es la última parte de la misión que me ha sido encomendada, y cuyos motivos debo ratificar aquí.

He de decir que, en parte se trata de una rendición de cuentas. Una raza es indigna de serlo mientras no justifica con obras su destino. Ustedes fundamentan la parte más alta de ese destino. Ante ustedes reconocemos en primer término, nuestro deber y nuestro derecho a mostrar lo que hemos realizado, las razones por las que no debemos ser olvidados por las que, creemos ser dignos de merecer, aquello que en vosotros puede haber de nosotros mismos.

El arte no sería nada si no fuese la facultad concedida a los hombres para que puedan intercambiar sus sueños, pasárselos de un corazón a otro. Es ese corazón nómada que cualquiera puede ponerse en el pecho. 
De lo que pretendemos persuadir a quien lo dude, es de nuestra convicción en la seguridad de que un mismo árbol de sangre y de espíritu puede dar su flor un día a orillas del Mediterráneo y otro día a orillas del Pacífico.

El arte expuesto os perténece y nos pertenece. Es vuestro al mismo título que nuestro. De forma que su exhibición no es una prueba del orgullo, sino de la confianza que unos hombres ponen en otros que son iguales a ellos.

España puede ofrecer "más" pero no puede ofrecer mejor. La obra de Goya, no pertenece al dinero, ni a la gloria : pertenece a la herencia de la tierra. Forma parte de esa herencia que podría permitir a nuestro planeta morirse en paz algún día. Haciendo atravesar el océano a este álbum de sus sueños, tenemos la certeza de no haber equivocado el camino.

En la tierra hollada por infinitos pasos, queda aún una huella, si queda alguna que vale la pena, y aun el atrevimiento de seguir : me refiero a la huella que dejan los poetas.

Es la huella de un poeta andino la que nos asegura que estamos donde debemos estar : es decir, junto al corazón de una gente que como la nuestra, "aun reza a Jesucristo y aun habla en español".

\section{Biblioteca de Letras "Jorge Puccinelli Converso"}

